\title{
O CINEMA ANTI-GUERRA
}

Tom Burns

UFMG

\section{RESU MO}

O presente trabalho procura estabelecer algumas características do filme anti-guerra a partir da premissa de que as diferenças culturais e raciais dos inimigos de guerra são apagadas e a noção de uma humanidade em comum, emotivamente atraente mas teoricamente problemática, é transmitida ao espectador. Argumenta-se, aqui, no entanto, que tal mensagem humanística não constitui uma proposta utópica para pôr fim à guerra, mas sim uma proposta que vem a contrapor a ideologia patriótica usada pelos governos para justificar a guerra.

\section{PALAVRAS-CHAVE}

filmes de guerra, filmes anti-guerra, patriotismo, humanismo

A idéia principal por trás da ficção, da poesia e do cinema anti-guerra não é apenas a de que a vida do ser humano é algo valioso demais para ser sacrificado, mas é também a de que um sentimento de "humanidade" comum prevalece à ideologia patriótica usada para se justificar as guerras. Parece-me que, de uma maneira ou de outra, todas as obras de arte anti-guerra partem dessa premissa. O poema "The man he killed" [O homem que ele matou], de Thomas Hardy, no qual um soldado britânico se pergunta por que matar um soldado inimigo, é um exemplo dessa idéia:

Had he and I but met

By some old ancient inn,

We should have sat us down to wet

Right many a nipperkin!

But ranged as infantry

And staring face to face

I shot at him and he at me,

And killed him in his place.

I shot him dead because -

Because he was my foe,

Just so; my foe of course he was;

That's clear enough, although

He thought he'd 'list, perhaps,

Offhand like - just as I -

Was out of work - had sold his traps -

No other reason why. 
Yes, quaint and curious war is!

You shoot a fellow down

You'd treat if met where any bar is,

Or help to half-a-crown.

O uso de vocabulário de um determinado campo semântico, o tom informal, porém meditativo, e a ausência de alusões literárias demonstram que a voz poética provém da classe trabalhadora, que constitui os combatentes dos exércitos modernos, e o fazem pressupor que a vítima era da mesma classe social que a sua. Ao buscar uma explicação para a morte do outro, só resta ao soldado concluir: "It was because — / because he was my foe" "[Foi porque - / Porque ele era meu inimigo]. A repetição da conjunção e a pausa, indicada pelo travessão, enfatizam que o soldado não evoca, ou não consegue evocar, uma motivação nacionalista para justificar seu ato. Como mostra a segunda estrofe, o fato de o outro (e não ele) estar morto devia-se apenas ao acaso. Na verdade, em outras circunstâncias, como diz a voz poética na última estrofe, ele teria até lhe emprestado algum dinheiro ou convidado a tomar uma bebida. Segundo o poema, então, a simples humanidade foi esquecida devido às circunstâncias absurdas da guerra ("quaint and curious"); em outras palavras, foi esquecida simplesmente porque dois homens usando fardas diferentes tiveram que se enfrentar no campo de batalha.

O favorecimento da noção de humanidade em vez da de nacionalismo fala diretamente a nós em termos humanistas e até sentimentais. No entanto, isso pode ser um pouco problemático, pois implica em dizer que as diferenças étnicas e/ou nacionais na verdade não importam — ou, se importam, não o bastante para justificar o massacre. Nosso senso comum de humanidade, bem como a aceitação e reconhecimento de tal noção, é considerado mais importante para a manutenção da paz. Ou seja, se as diferenças culturais não são aquilo que diretamente leva à guerra (que, na verdade, é conseqüência de diversos fatores econômicos e políticos complexos), elas são estrategicamente usadas pelo governo com o propósito de preparar a nação psicologicamente e garantir a força moral para suportar as dificuldades impostas pela guerra. Ambos os lados envolvidos nas duas grandes guerras do século vinte parecem concordar que, se a população civil pudesse ser levada a "odiar" o inimigo, então as guerras seriam lutadas com maior eficácia e determinação. A "demonização" do inimigo, que deveria resultar em uma rejeição emotiva da nação inimiga e em uma mobilização contra ela, foi tão significativa quanto os apelos patrióticos pelo esforço unido em defesa da pátria. De fato, essa demonização constituiu o lado negativo do apelo patriótico positivo.

Chega-se à rasura de traços humanos no inimigo, à demonização de seu caráter e à criação de estereótipos culturais basicamente de duas maneiras: treinamento militar e propaganda política. A primeira delas, com sua ênfase na repetição mecânica de exercícios físicos "by the numbers", objetiva alcançar ação e reação instantânea por parte do soldado. A excessiva aprendizagem desses movimentos causa um curto-circuito que impede o raciocínio, fazendo com que o soldado esteja pronto a obedecer a ordens em situações perigosas, em que a razão poderia levá-lo a ter mais cautela, e a matar, quando qualquer pessoa civilizada evitaria fazê-lo, por estar condicionado a pensar ser tal ato imoral. $\mathrm{O}$ corpo, treinado para pôr em prática movimentos ensaiados com o fuzil, a baioneta, a granada, será capaz de fazê-lo no momento certo e de modo decisivo, sem se deixar influenciar pelo lado racional ou emocional. 
A propaganda, por sua vez, dirige-se principalmente à população civil, apesar de poder servir também como método indireto de recrutamento de soldados, uma vez que grande parcela da população pode ser mais tarde mobilizada para o serviço militar. Por exemplo, o cinema propagandista britânico e norte-americano das duas grandes guerras retratou os alemães como bárbaros belicosos, impiedosos e sanguinários. Supõese que essa imagem tenha assegurado o apoio civil à guerra, fazendo inclusive com que a população tolerasse duras medidas políticas e econômicas impostas pelo governo. Também motivou o alistamento de jovens nas forças armadas (alguns deles fizeram-no para escapar à humilhação imposta pela sociedade àqueles que optaram por não atuar no serviço militar), para que pudessem dar sua própria contribuição para a destruição de um povo tão cruel. Filmes no circuito comercial radicalizaram esse estereótipo cultural, por vezes de modo cômico, como o prussiano com seu monóculo, de postura excessivamente rígida na marcha em passo de ganso; outro estereótipo, mais sutil, era o nazista fanático, sinistro, com suas intenções monstruosas disfarçadas por trás de um fachada sofisticada, um personagem facilmente identificado em qualquer filme de espionagem cujo pano de fundo é a guerra. Quer como bufão, quer fanático cruel, os "Hunos" (como foram denominados os alemães pelos aliados na Grande Guerra) foram desumanizados.

Por outro lado, vale observar que tanto o cinema britânico quanto o norteamericano buscaram mitigar ou diminuir diferenças culturais quando essas tornavam-se um problema entre os próprios aliados. As inúmeras tropas americanas na Grã-Bretanha, esperando a invasão da Europa nos anos finais da guerra, não eram, em muitos casos, uma presença muito bem-vinda. Os soldados americanos eram melhor remunerados do que os britânicos e seu modo de agir informal e espontâneo nem sempre fez com que fossem mais aceitos pela população local menos aberta (reclamava-se, por exemplo, de que os ianques eram "overpaid, oversexed, and over here").

Embora as causas desses conflitos culturais fossem registradas nos filmes, "o objetivo principal dos cineastas (em ambos os lados do Atlântico) era reconciliar as diferenças e enfatizar as aspirações comuns dos aliados anglófonos". ${ }^{1}$ Por essa mesma razão, o Ministério de Informação Britânico colaborou com o Gabinete de Informação de Guerra dos Estados Unidos na produção de filmes ou no apoio a produções independentes, cuidadosamente escolhidas. Em ambos os casos, os cineastas tendiam a mostrar a colaboração angloamericana, em vez de seus conflitos, e a promover uma compreensão "humana" básica, ou até uma mesma tradição cultural, apontando as diferenças como superficiais.

No filme anti-guerra, os estereótipos inculcados pelo treinamento militar e pela propaganda política aqui mencionados tendem a ser ignorados. $\mathrm{O}$ soldado inimigo é retratado como uma pessoa "como nós", isto é, alguém que apenas deseja sobreviver à guerra. $O$ primeiro passo para se contrapor à demonização do inimigo no filme anti-guerra é estabelecer sua humanidade, o que implica torná-lo visível. Tal processo ocorre, por exemplo, no filme A midnight clear (1992), de Keith Gordon, cujo título alude à conhecida canção natalina. O filme narra as aventuras de um esquadrão especial de reconhecimento composto por soldados bastante jovens e inteligentes, em 1944, durante o último ano do teatro de guerra europeu. Seis desses rapazes são mortos já no começo, enquanto os

${ }^{1}$ Coultass. Images for battle: British film and the Second World War (1939-1945), p.168. 
remanescentes seguem em missão de reconhecimento pela floresta Ardennes, onde se defrontam com alemães em igual número. Temendo o ataque final no qual seriam mortos, os alemães planejam uma aproximação gradual entre eles, para, então, renderem-se.

Essa aproximação dá-se, inicialmente, por meio de um boneco de neve, feito pelos alemães, que carrega um bilhete. Nos encontros seguintes, os alemães vão aos poucos se tornando visíveis, até o ponto de haver entre os inimigos uma comemoração natalina com árvore de Natal, canções tradicionais e troca de presentes. Os soldados americanos, novatos que se deixam facilmente impressionar, não estão muito ansiosos por matar, muito menos matar aqueles de seu convívio. Os alemães só podem se render após a simulação de um combate; caso contrário, suas famílias seriam perseguidas. Depois de alguma negociação, os dois esquadrões concordam em encenar um combate, disparando suas armas e deixando os cartuchos vazios como prova. Os alemães, então, se "renderiam", mas o plano falha de modo trágico: um soldado americano mentalmente desequilibrado, que não havia participado da negociação, surge repentinamente e, sem compreender a trama, mata dois dos soldados alemães e deflagra o tiroteio. Vários homens são mortos, inclusive todos os alemães. Os sobreviventes americanos concordam em passar adiante a história de que o rapaz desequilibrado salvou sozinho todo o esquadrão, que havia sido atacado pelo inimigo. Assim, ele será condecorado e ninguém descobrirá a verdade.

Se, por um lado, A midnight clear sugere que na Guerra não é possível se fazer uma paz individual, por melhor que sejam as intenções, por outro lado o contato pessoal, o reconhecimento de uma humanidade comum supera as diferenças nacionais e a hostilidade "oficial" - e isso é um tanto contraditório em relação à primeira afirmativa, uma vez que sugere que não cabe à decisão individual abolir a guerra. $\mathrm{O}$ filme pode estar aludindo à trégua natalina de 1914, quando soldados dos dois lados da frente ocidental saíram das trincheiras, aparentemente por vontade própria, e trocaram fotografias e cigarros na terra-de-ninguém. Seus respectivos oficiais ficaram furiosos com a confraternização pouco militar entre os soldados, e nos Natais seguintes evitaram que o mesmo acontecesse, planejando investidas para esta data.

\section{II}

Soldados de ambos os lados da Primeira Guerra Mundial, como se pode notar na epistolografia e na ficção, odiavam os civis mais do que os soldados inimigos - que eles invariavelmente respeitavam - , o que significa dizer que a propaganda oficial era menos eficaz que a experiência das trincheiras. Isso fica evidente, por exemplo, no clássico anti-guerra hollywoodiano All quiet on the western front, uma adaptação feita por Lewis Milestone, em 1930, do romance alemão de mesmo título, de Erich Maria Remarque. A postura anti-guerra de Remarque é fortemente mantida, pois o filme se recusa a encontrar qualquer aspecto da guerra que mereça ser comemorado e aponta o contraste (como Remarque de fato o fez em sua obra) entre o modo como a guerra foi representada para os civis e como foi realmente vivenciada pelos soldados. Estes questionam a razão para a guerra nos seus diálogos (“Como pode um país ofender o outro?", pergunta um deles; "Você quer dizer uma montanha na Alemanha ofender um prado na França?") e falam sobre a futilidade e a aparente qualidade de interminável da guerra (“'Avancem até Paris'. Então é assim que eles falam fora das trincheiras", diz um veterano ao outro). Apesar de esses soldados alemães soarem, de modo cômico, como os norte-americanos de inúmeros 
filmes hollywoodianos sobre outras guerras, isso paradoxalmente aponta para a popularidade universal do romance de Remarque na época de sua publicação. A experiência das trincheiras era semelhante para ambos os lados, e pessoas dos países aliados conseguiram simpatizar com os soldados alemães do romance. No entanto, uma explicação bastante lógica em relação ao sucesso do filme nos Estados Unidos (All quiet on the western front ganhou o Oscar de melhor filme do ano) foi o fato de os "inimigos" serem franceses, e não americanos. O questionamento do patriotismo presente no filme também pode ter sido permitido por ter partido dos alemães, e não dos americanos. ${ }^{2}$ De qualquer modo, é importante ressaltar que existia a possibilidade de um filme anti-guerra ser um sucesso nos Estados Unidos antes da Segunda Guerra Mundial. E tamanho foi o efeito de sua mensagem anti-guerra para o público europeu que o filme foi censurado tanto na França quanto na Alemanha.

Já no início do filme, o diretor da escola motiva os alunos a se alistarem, a fazer "um grande sacrifício pelo nosso país”, e até cita, mostrando aprovação, a notória frase horaciana (Dulce et decorum est pro pátria mori), que o poeta inglês Wildred Owen, morto em uma batalha fútil pouco antes do fim da guerra, chamou de "aquela velha mentira" em seu conhecido poema sobre homens mortos pelo gás usado em um ataque. Os estudantes se levantam e gritam com grande entusiasmo "Irei!" - cena que, efetivamente, demonstra o poder da retórica nacionalista (o equivalente verbal do desfile e da banda militares em filmes de fundo patriótico) de levar jovens à morte. $\mathrm{O}$ soldado Paul Baumer (Lew Ayres), de licença, aparece na escola para deitar por terra a propaganda feita pelo professor e talvez poupar a próxima leva de vítimas; porém, ao tentar expor a verdade sobre a guerra, é chamado de covarde. Da mesma maneira, os velhos, sentados no bar, com um mapa das frentes de ataque sobre a mesa, dizem-lhe que sua experiência (real) é por demais limitada para uma compreensão adequadamente estratégica da guerra e de como conduzi-la. Esse é o "ponto de vista do general" que age fora das trincheiras, em contraste com o dos soldados em ação.

Cenas como aquela em que a explosão de uma bomba deixa um homem cego enquanto outro entra em estado de choque na trincheira, ou em que o sargento durão Himelstoss se esconde amedrontado, ou ainda em que os soldados se defendem de uma invasão de ratos, refletem experiências autênticas das trincheiras e escapam aos clichês dos filmes de guerra. A cena em que os soldados alemães discutem quem deve herdar as botas de fabricação inglesa de um camarada, junto ao seu próprio leito de morte, constitui um ótimo exemplo da adaptação de uma cena ficcional para a tela. O autor obviamente buscou mostrar a insensibilidade para com os soldados que podem morrer a qualquer instante e para quem pequenos confortos são de grande importância. Essa cena repete-se no filme, tendo seu impacto intensificado à medida que as botas são usadas por vários membros do esquadrão que, um a um, vão morrendo. Apesar do diálogo um tanto artificial, o episódio central do romance, em que Baumer enfrenta um soldado francês no local de explosão de uma bomba de canhão - na verdade, o primeiro inimigo com quem se defronta e que tem que matar de perto - é bastante carregado de emoção. O encontro face-a-face visto no poema de Thomas Hardy repete-se aqui em um contexto macabro: Baumer dirige-se ao cadáver, vê

${ }^{2}$ Cf. Roguemore. History goes to the movies, p.139; CARnes. Past imperfect: History according to the movies, p.191. 
as fotografias de sua família, chora e lamenta tê-lo matado.

Por sua vez, o filme em preto e branco de Stanley Kubrick, intitulado Paths of glory (1957), parece fugir do modelo básico de filmes de guerra. Nele, o inimigo exterior permanece oculto, mas o adversário interior é bastante explícito: nomeadamente, a hierarquia militar do exército francês. O corajoso Coronel Dix (Kirk Douglas), um advogado de caráter, não consegue defender os homens de sua unidade das armadilhas cruéis do Comandante (George Macready), que exige uma recompensa pelo fracasso do ataque - a marcha do batalhão, em campo aberto, em direção ao fogo pesado, comuns nas batalhas da Primeira Guerra Mundial — e os manda fuzilar. Os três a serem executados deveriam ser escolhidos arbitrariamente, porém apenas um o é: o segundo é eleito por ter um distúrbio mental e o último por ter questionado o tenente do pelotão (este, ironicamente, recebe a ordem de dar o coup de grâce).

Apesar de o filme ser mais anti-militar do que anti-guerra, seu contexto histórico é o incidente ocorrido em novembro de 1915, quando um batalhão francês recusou-se a sair das trincheiras em Vimy. Todo o batalhão foi levado à corte marcial e, como bodes expiatórios, dois homens - um homem de cada companhia — foram fuzilados. O retrato da rigidez militar e sua estupidez, a ineficiência e a insistência em ataques frontais fatais, o distanciamento entre oficiais da frente e os de gabinete, bem como entre os oficiais e os soldados — tratados como bucha de canhão —, são temas já conhecidos na história da Primeira Guerra Mundial, que ecoam em diversas representações fílmicas e ficcionais.

O contexto histórico do filme de Kubrick é bem mais convincente do que o de Johnny got his gun (1971), de Dalton Trumbo, um filme anti-guerra dogmático que opta por uma quase-caricatura, ao passo que Paths of glory emprega a ironia. No filme de Trumbo, um soldado norte-americano (Timothy Bottoms) é mutilado por uma bala de canhão; seu horror cresce à medida que percebe estar cego, surdo, mudo, ter seus braços e pernas amputados e seu rosto completamente desfigurado, mas, infelizmente, seu cérebro e seu sistema nervoso ainda funcionam e o levam à consciência de seu estado. Ele é mantido vivo com o propósito da pesquisa médica, uma vez que os outros não percebem estar ele consciente. Privado totalmente de controle motor e de seus cinco sentidos, ele apenas consegue pensar na contagem do tempo, como sua única maneira de confirmar sua presença no mundo. Sua condição presente no hospital militar é intercalada por flashbacks de sua vida antes do acidente, que levam diretamente à crítica proposta por Trumbo: o progresso científico às custas do sofrimento humano, a falsidade da ideologia nacionalista, da religião organizada, e as banalidades verbais diante da guerra moderna - tudo isso visto como elementos que perpetuam a guerra.

Em Johnny got his gun, o pai diz ao soldado, ainda quando criança, que um dia ele "tornará o mundo seguro para a democracia" (uma alusão pouco provável à notória frase do presidente Wilson). "O que é a democracia?", pergunta o menino. "Não tenho muita certeza, mas acho que tem algo a ver com jovens matando uns aos outros" resposta que um pai pouco provavelmente daria a seu filho, o que enfatiza o caráter propagandista do filme. Mais eficaz, porém, é a fantasia do soldado, em que seu pai é apresentador de um show de aberrações de um circo, gritando "Joe Bonbon, o homem sem braços e sem pernas, o espetáculo do mundo". A natureza grotesca da situação, que reflete, sobretudo, a condição real do personagem mutilado, garante a autenticidade da cena. O show de aberrações é a proposta do próprio personagem, assim que consegue se 
comunicar com os médicos através do código morse, com movimentos da cabeça: "Quero sair daqui, para que as pessoas possam ver como estou. Ponham-me em um circo, para que possam me ver", e ver também o que a guerra é capaz de fazer. Quando seu pedido é recusado, ele sinaliza com um movimento da cabeça: "Então me matem", frase que repete incessantemente. Uma enfermeira piedosa tenta sufocar o rapaz com um travesseiro, mas é surpreendida por um médico, que o tranca para sempre na escuridão literal e metafórica de um armário. Apesar de tão amargo quanto Paths of glory, a mensagem anti-guerra de Johnny got his gun talvez seja menos eficaz por se tratar mais de um filme de terror ahistórico.

\section{III}

O presente trabalho sugere até aqui que o filme anti-guerra pode ser baseado em uma guerra específica, tal como a Primeira Guerra Mundial (pouco defendida), como é o caso de All quiet on the western front, ou baseado na guerra em geral, como é A midnight clear, cujo contexto histórico é a Segunda Guerra Mundial (geralmente tida como necessária para pôr um fim ao fascismo), ou mesmo baseado na mentalidade militar que torna as guerras tanto possíveis quanto prováveis, sendo Paths of glory o melhor exemplo. O filme anti-guerra pode ainda ser anti-racista, uma vez que idéias racistas contribuem para conflitos nacionais. A demonização do inimigo torna-se mais fácil quando a nação inimiga é uma raça Outra, não-ocidental, pois a diferença racial cria uma categoria em que o inimigo pode ser visto ou mostrado como sub-humano. Que isso ocorre mesmo sem propaganda explícita do governo, como resultado de preconceitos, está evidente em certas atitudes norte-americanas para com os japoneses às vésperas da Segunda Guerra Mundial: eles pareciam "uma raça engraçada... eram atarracados, com pernas arqueadas, e dentuços". ${ }^{3}$ A maioria dos soldados americanos, que tinha visto prisioneiros japoneses, confessava sentir "ainda mais vontade de matá-los", ao passo que, aqueles que tinham visto prisioneiros alemães, os viam como "homens como nós". ${ }^{4}$ ○ filme anti-guerra, nesse caso, deve tentar apagar diferenças raciais e culturais visíveis e, mais uma vez, promover um sentimento de humanidade comum que se manifeste contra a matança.

O ponto em comum que marca os dois filmes seguintes como essencialmente antiguerra é, portanto, a rasura da diferença racial e do reconhecimento do caráter humano do inimigo não-europeu. Essa é a premissa do filme Hell in the Pacific (1968), de John Boorman, que foi lançado durante a Guerra do Vietnã. Nesse conflito equivocado, a elite política e militar norte-americana engajou os Estados Unidos em uma guerra asiática colonial contra um inimigo que poderia ser demonizado tanto em termos de racismo ("gooks") quanto em termos ideológicos da Guerra Fria (“comunistas").

A partir do paradigma face a face, o filme narra a história de um oficial americano e de um japonês, que se encontram isolados em uma mesma ilhota do Pacífico, supostamente durante da Segunda Guerra Mundial. O confronto decorre da hostilidade instintiva diante da presença inimiga, mas a expectativa do ataque não leva à iniciativa individual dos adversários, que se retiram. Após a perseguição, o americano (Lee Marvin) é capturado e tratado como escravo - carregando uma cangalha pela praia, como um

${ }^{3}$ Manchester. American Caesar: Douglas MacArthur (1880-1964), p.188.

${ }^{4}$ KeEgan. The face of battle, p.298. 
animal. Todavia, a expectativa hollywoodiana de brutalidade estereotipada por parte do japonês é lançada por terra quando a situação é invertida e o oficial japonês (Toshiro Mifune) é capturado e tratado da mesma maneira. Ambos os homens terminam por se dar conta da insensatez em se manter um prisioneiro de guerra em situação de sobrevivência. Apesar de os manuais de instrução de guerra determinarem o "extermínio" do prisioneiro em tais situações, o papel de captor-capturado desenrola-se em dois indivíduos livres, com uma mútua desconfiança, o que, por sua vez, culmina com a cooperação mútua na busca de alimento e água e na construção de um barco, com que esperam navegar até uma ilha maior. Tal rejeição do procedimento militar padrão e a boa vontade em colaborar com o inimigo leva à esperança, pelo menos em termos individuais, de que a guerra possa ser humanisticamente superada - esperança que, igualmente, será lançada por terra.

Em uma leitura superficial, pode-se interpretar o filme como a história de dois soldados inimigos que fazem sua guerra particular em uma ilha deserta. Entretanto, a guerra é, por definição, um conflito político que envolve material e grandes contingentes humanos por um vasto território. Nesse filme, pois, a redução de dois exércitos a dois homens, o confinamento do território a uma ilhota, bem como a transformação do conflito político, econômico e ideológico de grande escala (embora a única referência histórica à Segunda Guerra seja icônica — as fardas) em uma simples luta de poder individual, sugerem uma parábola.

Trata-se, aqui, de uma parábola de cunho anti-guerra, uma vez que a situação dos inimigos remete à dos adversários anônimos do poema de Thomas Hardy. Não se trata, aqui, de dois homens da classe trabalhadora, mas sim de indivíduos da mesma classe dominante na hierarquia militar (dois capitães), cujo propósito absurdo é eliminar o Outro, apagar sua existência dentro de um contexto político já irrelevante. De modo contrário, haveria a possibilidade de colaboração no novo contexto, se possível fosse ignorar o anterior. A necessidade de reconhecer o Outro, de enxergar sua humanidade, é percebida quando os dois chegam à nova ilha, onde encontram indícios de ocupação tanto por parte dos japoneses quanto por americanos. A ambigüidade em relação a quem tem o controle da ilha (antes de se darem conta de que, na verdade, ela está deserta) faz com que temam pela vida um do outro. Ao ser surpreendido por seu companheiro japonês, o capitão americano diz: "Por um momento, pensei que você fosse um japa". A ironia cômica - pois seu companheiro é de fato um "japa” - revela como o Outro passa a ser visível à medida que se torna familiar, desdemonizado, um de nós.

Como uma espécie de "dupla de Robinson Crusoés" - a patente igual dos dois homens impede que o personagem japonês seja tratado como um "Friday" submisso —, eles saqueiam o abrigo militar em busca de mantimentos, roupas, cigarros e bebida. Enquanto embriagam-se bebendo saquê (o que evoca mais uma vez o poema de Hardy), comportam-se de maneira civilizada, cordial, pondo em suspensão suas nacionalidades e seus conflitos. No entanto, essa simples idéia não pode prevalecer no mundo. No poema de Hardy, o soldado está pensando n'o homem que ele matou, que, como sugere o uso ambíguo do pronome de terceira pessoa no título, podia ter sido ele próprio. No filme, o oficial japonês pega um fascículo da revista Life, que contém fotografias cruas de prisioneiros, civis e soldados japoneses mortos, e seu ódio cresce à medida que a folheia, enquanto o americano, desconhecendo tal estado de espírito e bêbado, pergunta-lhe: 
“Por que vocês não acreditam em Deus, no céu, ou em Jesus Cristo?" O cliché hollywoodiano de uma nação cristã, patriótica, defendendo seus valores contra estrangeiros bárbaros é, assim, exposto e ridicularizado.

Há, porém, uma ironia ao se comunicarem através de gestos, de ações, de mímica, enquanto continuavam a falar suas línguas mutuamente ininteligíveis, cada um fingindo ser compreendido pelo outro. A insistência em falar sem ser compreendido pode constituir um ritual "dramático", um gesto que preserva a humanidade e a sanidade de cada um, uma vez que a língua falada, estrutura básica de uma cultura, é o meio através do qual nos inserimos no mundo social. Porém, a função comunicativa da linguagem volta a se impor: o fingimento cede, mas a ironia prevalece, quando o personagem japonês diz ao outro para "calar a boca", e o outro, compreendendo apenas seu tom hostil, responde: "Você não pode falar assim comigo." Retoma-se, com essa troca de palavras, a hostilidade inicial - hostilidade que é fomentada pela obscenidade das fotografias e pela mútua falta de compreensão lingüística, anteriormente ignorada ou perdoada.

Há ainda uma ironia cultural no fato de a revista Life, especializada em divulgar fotografias de propaganda para os aliados, aqui, supostamente, retratar a presença da humilhação e morte dos japoneses que "motivaram" os leitores na frente doméstica, exceto quando, como no filme, elas foram vistas justamente por um japonês. O olhar do Outro é reinstituído, paredes são erguidas, a hostilidade recomeça.

A complexidade da questão não se resolve com o final aparentemente simples e conclusivo, em que a bomba atirada de um avião não identificado explode no abrigo, matando os dois. Não sabemos a quem pertencia o avião, ou que adversário foi responsável pela bomba lançada, mas isso pouco importa. A leitura desse texto como parábola antiguerra pode levar à seguinte conclusão: em qualquer conflito armado, seres humanos e a dignidade humana serão as vítimas; pode ainda sugerir que a guerra não pode ser ignorada e que dela não se pode escapar. Os dois soldados estão sempre presos às suas identidades de conflito mútuo, que pode ser resolvido somente com a morte de um deles, ou de ambos. Mais uma vez, como em A midnight clear, parece que, no contexto da guerra, não pode haver paz individual.

A técnica de paralelismo utilizada para enfatizar a condição humana do "inimigo" e, assim, expor as falsidades da ideologia nacionalista ao retratar a guerra, pode também ir além do indivíduo e chegar ao grupo, como em None but the brave (1965), dirigido por Frank Sinatra. Esse filme foi a primeira co-produção nipo-americana e, apesar do conservadorismo político notório do diretor, consegue evitar alguns dos estereótipos mais comuns dos filmes de guerra. No arquipélago Salomões, vêem-se os indícios de uma invasão anfíbia, um pelotão de japoneses náufragos construindo um barco, na tentativa de fugir da ilha. O Tenente Kuroki difere do típico oficial nipônico fanático dos filmes hollywoodianos. Em primeiro lugar, fala japonês, exceto com a narração voice-over em inglês de seus pensamentos íntimos - que, se legendada, seria bastante dispendiosa do ponto de vista cinematográfico. Sua preocupação maior é manter seus homens vivos na ilha deserta e sobreviver à guerra, em vez de morrer orgulhosamente em nome do imperador - como é comum nesses filmes de guerra. $\mathrm{O}$ sargento de seu pelotão, por outro lado, cujo entusiasmo ele precisa reprimir, ilustra tal tipo de personagem: "Não há honra maior que morrer pelo seu país", ele braveja, na versão japonesa da frase horaciana. Logo depois, cai na ilha um avião americano levando o mesmo número de fuzileiros 
navais, que são guiados também por um sensato piloto veterano que, por sua vez, é importunado por um inexperiente, mas rígido, tenente, representando o correspondente americano do fanático sargento japonês.

Os adversários estão, portanto, equilibrados: em ambos os casos, um pelotão pronto para combate, guiados por um líder experiente e moderado, e subordinados fanáticos dispostos a assumir a liderança, subvertendo sua autoridade militar e sua capacidade. A situação paralela, que remete ao paralelismo de cunho individual de Hell in the Pacific, parece anunciar um mini-conflito pelo controle da ilha, mas esta é posta em segundo plano. Esse conflito externo entre os dois lados, pois, apresenta um conflito interno em cada um dos lados: moderação versus fanatismo e racionalidade versus impetuosidade na conduta militar.

A troca de cigarros por peixes funciona como prenúncio de uma maior compreensão (e talvez do capitalismo nipo-americano pós-guerra) ou, pelo menos, indica a disposição para negociar, mas quando a bandeira japonesa incita o disparar fogo de um navio americano, ao invés de receber resgate, deflagra-se, de fato, uma mini-guerra. Os americanos iniciam um ataque para tomar controle do barco, mas este é afundado por uma granada. Ao contrário da maioria dos filmes de guerra hollywoodianos, a violência não é impessoal: os dois lados sofrem perdas visíveis, enterram e fazem luto por seus mortos. Após esse incidente, os dois comandantes decidem negociar e, embora um não confie no outro, chegam a um acordo: os americanos providenciam atendimento médico ao amputarem a perna de um soldado japonês ferido, em troca da água potável controlada pelos japoneses. Ambos os líderes, desconhecendo a força do adversário, fazem suas próprias forças parecerem maiores do que realmente são, mas o diálogo entre eles assinala a vontade de chegar à paz: "Por que estamos tentando matar um ao outro?", pergunta um deles; "É um antigo costume tribal" é a resposta. Em seu apelo apolítico à humanidade, superando a natureza humana da antropologia crua e aparentemente deixando de lado as diferenças nacionais, esse diálogo parece também esquecer a história. Isso é possível porque a ilha, de fato, não tem valor estratégico, e, portanto, os dois lados atingem, civilizadamente, a coexistência pacífica. Após alguns episódios tensos, uma tempestade — isto é, uma tribulação natural, e não forjada pelo homem — faz com que os adversários colaborem um com o outro. Em seguida, os dois comandantes contam histórias pessoais de suas vidas antes da guerra, alcançando uma certa simetria humana.

Ao re-estabelecer contato e chamar socorro, o operador de rádio americano interrompe a trégua: ou seja, a tecnologia americana impõe novamente a condição bélica, e os japoneses, cujo código de honra não permite que se rendam, assumem uma nova posição de defesa, declarando que tentarão impedir o resgate dos americanos (notem-se, aqui, os clichês culturais da tecnologia americana e do código de honra japonês, que não podem ser evitados). Os comandantes entendem a nova situação, mas os soldados de ambos os lados agora relutam em matar uns aos outros após o episódio de confraternização. O desfecho é inevitável, com a morte de todos os japoneses no tiroteio, fato que, entretanto, não deve ser interpretado como uma vitória "militar" norteamericana, uma vez que os japoneses, se tivessem sobrevivido, continuariam apenas a viver na ilha sem esperança. E, se fosse uma vitória, seria uma vitória de Pirro, pois apenas cinco americanos conseguem escapar. A legenda final - "Ninguém vence" — é 
a mensagem pacifista por excelência.

Pode-se até certo ponto dizer que essa mensagem, apesar de emocionalmente satisfatória, não constitui uma solução para o problema real da guerra, que é lutada com fins políticos e econômicos e que, portanto, deve ser interpretada como um capítulo final para um dos lados (nenhum dos adversários numa guerra real jamais desistiria e partiria, como foi o caso da Primeira Guerra Mundial, mesmo estando todas as tropas exaustas). Aqui reside o aparente ponto fraco do filme anti-guerra: a falta de explorar os conflitos políticos que induzem às guerras. $O$ apelo emocional não tem, é claro, o poder de pôr fim às guerras, como a negociação racional o tem. Entretanto, como mostram os exemplos aqui estudados, em nenhum desses filmes a tentativa individual de alcançar a paz logra sucesso. Pelo contrário, eles mostram que aqueles empenhados em alcançar a paz morrem tão rapidamente - ou talvez mais ainda - que aqueles resignados a lutar. Conclui-se, pois, que a proposta do filme anti-guerra não é utópica, mas é, sim, pregar valores morais mesmo no contexto amoral do fazer guerra. Instiga-se, assim, a reflexão e o posicionamento que desnudam o patriotismo ufanista e subvertem a propaganda enganosa dos governos que promovem os conflitos internacionais. ${ }^{5}$

\begin{abstract}
A B STRACT
This paper attempts to establish the parameters of the antiwar film, the basic premise of which is that the cultural and racial differences of enemies in war are erased, and an emotionally appealing but theoretically problematic notion of a commonly shared humanity is made to the viewer. Various examples are examined. It is argued that this humanistic message is not intended as a utopian proposal for the end of war, however, but to counteract the patriotic ideology propounded by governments to justify wars.
\end{abstract}

\title{
KEY-WORDS
}

war films, anti-war films, patriotism, humanism

\section{REFERÊNCIAS BIBLIOGRÁFICAS}

Carnes, Mark C. et al (eds.). Past imperfect: History according to the movies. New York: Henry Holt, 1995.

Coultass, Clive. Images for battle: British film and the Second World War (1939-1945). Newark: University of Delaware Press, 1989.

KeEgAn, John. The face of battle. New York: Barnes \& Noble, 1976.

Manchester, William. American Caesar: Douglas MacArthur (1880-1964). New York: Dell, 1978. Roguemore, Joseph. History goes to the movies. New York: Doubleday, 1999.

${ }^{5}$ Este texto foi traduzido do original inglês por Glaucia Gonçalves e pelo autor. 